\title{
UNA CONTRIBUCION MEXICANA Y COSTARRICENSE AL DERECHO URBANISTICO LATINOAMERICANO
}

por

León Cortiñas-Peláez

Catedrático por oposición y coordinador del Taller de Derecho Administrativo y Derecho de las Finanzas Públicas en la Universidad Nacional Autónoma de México Investigador honorario de la Fundación Alexander von Humboldt

SUMARIO: I. MEXICANOS EN COSTA RICA. - II. LA CONCEPCION LIBERAL DE LA CIENCIA JURIDICA. - III. EL DERECHO COMO REGLA MAS PODER.-IV. UN MAESTRO MALOGRADO.-V. HACIA UN DERECHO ESTRUCTURAL.-VI. VIVIENDA Y PLANEACION NACIONAL.-VII. LO NORMATIVO COMO ESTORBO SOCIAL.-VIII. LO HABITACIONAL, EFECTO Y NO CAUSA.- IX. HACIA LA SUPERACION DE UN DERECHO DE CLASE. - $X$. URBANISMO Y PARTICIPACION. XI. UN FALSO ATRIBUTO DE LA PROPIEDAD PRIVADA.XII. CONTENIDO FORMAL DE ESTA CONTRIBUCION. XIII. EL «ESTUDIO»Y SU DOCTRINA. - XIV. EL OBJETO DEL DERECHO URBANISTICO.-XV. LOS ACTOS «URBANISTICOS» DEL PODER PUBLICO.-XVI. LIMITACIONES CONCEPTUALES: TECNICA JURIDICA NUEVA Y SISTEMA TRADICIONAL. - XVII. DE LAS LIMITACIONES ESTRUCTURALES.-XVIII. UN NUEVO DIALOGO. 


\section{MEXICANOS EN COSTA RICA}

De la creciente presencia del horizonte latinoamericano en la ciencia jurídica mexicana testimonia una prolija investigación aplicada, realizada por un grupo de urbanistas mexicanos en Costa Rica, a comienzos del sexenio mexicano $1976-82$ (1), poco tiempo después de entradas en vigencia las adiciones y modificaciones a la Constitución General de los Estados Unidos Mexicanos (arts. 27, 73 y 115) y de ser promulgadas las disposiciones de la Ley General de Asentamientos Humanos de 26 de mayo de 1976 y la Ley del Desarrollo Urbano del Distrito Federal de los Estados Unidos Mexicanos (2).

\section{LA CONCEPCION LIBERAL DE LA CIENCIA JURIDICA}

América latina se encontraba y encuentra -como consecuencia del fracaso de las estructuras agrarias dependientes y del crecimiento desorbitado de urbes- carente de una industrialización suficiente ante el surgimiento de una conflictiva económica y social para la cual no han sido preparadas estructuras normativas idóneas, debido, principalmente en lo jurídico-formal, a la mentalidad individualista y a las técnicas anticuadas todavia dominantes en la casi totalidad de las Facultades latinoamericanas.

En efecto, la concepción liberal de la ciencia jurídica coincide con la postura abstencionista del Poder público, desconoce la necesidad de principio (y no supletoria) de la acción administrativa en la configuración eficiente (y no simplemente escrita y retórica) de los derechos individuales y sociales e ignora la misión decisiva que tienen la organización y el funcionamiento de la Administración pública en el fortalecimiento de las libertades concretas. Coincidencia, desconocimiento e ignorancia cuya superación impone una integración de los valores político-sociales de las instituciones $\mathrm{y}$, particularmente, de la Constitución en el estudio del Derecho público, que es - por naturaleza, y debe ser por imperativo científico- un Derecho político. La construcción lógico-formal de LABAND, cuyo ejecutor testamentario ha sido KELSEN, ha llevado en el segundo tercio

(1) Andrés Alarcón-Segovia (director): Estudio jurídico-urbanístico de la legislación de la República de Costa Rica, Ciudad de México: Estudios y Proyectos, S. A., 4 vols., $153+325+161+203$ ff., 1977-1978.

(2) Cfr. la obra colectiva Asentamientos humanos, urbanismo y vivienda, Ciudad de México: Porrúa e Infonavit, 1977, 788 págs., especialmente 453 a 540. 
del siglo xx latinoamericano a convertir a la ciencia juridica en una especie de geometría normativa, que menosprecia toda consideración e integración en el Derecho de valores históricos, sociales y económicos; políticos, en definitiva.

La coyuntura latinoamericana en este umbral de crisis generalizada que ilustra el tercer tercio del siglo xx le añade así, en lo puramente técnico, una rarefacción formalista y un empobrecimiento conceptual increíbles del ser del Derecho, siendo la ciencia pretendidamente pura del Derecho una deformación completa del orden jurídico existente en la realidad, una especie de "ciencia jurídica sin derecho", como la llamara HeLler, que coincide históricamente con una completa incapacidad para resolver los verdaderos problemas que asaltan a la ciencia jurídica en cuanto rama de las ciencias sociales.

\section{EL DERECHO COMO REGLA MAS PODER}

En el Derecho público de los países exportadores de materias primas urge la oposición -al positivismo jurídico y a sus epígonos- de un método de realismo jurídico que integre en el fenómeno "Derecho» no sólo la pura norma, sino también sus elementos históricos extranormativos, los elementos económicos, sociales y políticos de lo jurídico. El «ser del Derecho» supone la integración dialéctica de elementos de Regla y de elementos de Poder, puestos de manifiesto estos últimos en los factores económicos, sociales y políticos. Por ello, la determinación del dominio de aplicación de una regla jurídica impone investigar, además de sus elementos estructurales y puramente normativos, el interés protegido por ella, y si otros intereses jurídicos protegidos por la Constitución tienen un mayor valor que el protegido por dicha disposición, para luego rematar en una interpretación extensiva o restrictiva.

Es partiendo de estas consideraciones y reservas generales que cabe reflexionar sobre el indicado Estudio de ALARcón, cuyo normativismo marcado no le impide ciertamente el que se le considere como una contribución de vanguardia a la reflexión puramente técnico-jurídica sobre la problemática urbanistica y habitacional. 


\section{UN MAESTRO MALOGRADO}

Licenciado en Derecho por la UNAM con una tesis sobre Sociedad, ciudad, planeación y Derecho urbano; Maestro en Planeación Urbana por la Escuela Nacional de Arquitectura de la UNAM y posgraduado en Derecho Urbanístico por la Universidad Complutense de Madrid; fundador y titular de la cátedra de Derecho Urbanístico en la misma ENA, cuyo Acervo Bibliográfico de posgrado hoy lleva su nombre; catedrático de Legislación Ambiental e investigador del Centro de Estudios del Medio Ambiente (Atzcapotzalco) y profesor de Legislación Urbanística (Xochimilco) en la Universidad Autónoma Metropolitana. Tal fue la vida académica del joven maestro Andrés Alarcón-Segovia (1943-79), que nos ha sido arrebatado cuando más cabía esperar de sus ya fecundas investigación y docencia y de su profunda cultura.

Espíritu generoso, luchador incansable, enriqueció en la bibliografía mexicana el lenguaje interdisciplinario de los Asentamientos Humanos y del Urbanismo con los conceptos de eficacia, de seguridad jurídica y de justicia; su talento y su inquietud le llevaron a forjar cátedras, crear cursos, dar conferencias y escribir artículos y estudios en los cuales, sin apartarse del rigor académico, buscó la forma de influir en consideraciones de orden económico y social, que le dieran a su esfuerzo la dimensión de saber universal que debe ser patrimonio de la Universidad. En ésta, en particular, y enfrentándose a la incomprensión de los "pobres de espíritu», defendió en el claustro de la Universidad Metropolitana el derecho indiscutible de proponer la creación de campos de estudio e investigación que se apartaban de los moldes tradicionales de enseñanza; los muros de Aztcapotzalco, sede de uno de los centros pioneros en la investigación jurídica de América latina, recuerdan que este universitario - de corazón y de espíritu, que vivió y murió en el seno del quehacer universitario- dio base y solidez jurídicas al Centro de Estudios del Medio Ambiente (CEMA) con sus argumentaciones prolijas y tesoneras, que pugnaron siempre por abrir nuevas brechas. en el horizonte del conocimiento.

La dirección de la obra colectiva que motiva estas páginas se inserta en el impulso creador que iniciara la tesis citada y que continuaron, entre otras, las publicaciones siguientes: Análisis comprobados de soluciones jurídicas para los usos del suelo, Ciudad de 
México: OEA, DDF y Colegio de México, Memoria, 1973; Aspectos jurídicos urbanisticos, Estado de México: AURIS, 1973; Fundamentos constitucionales y principios de Derecho urbanistico, UAM, 1975; Los problemas del Area Metropolitana, IEPES, 1975; «Hacia un Derecho urbanístico: el caso de México", Ciudad de México: Revista Mexicana de Comercio Exterior, 1976; «Aspectos metodológicos del Derecho urbanístico», Ciudad de México: Revista CIDIV (INDECO), 1976; «Plan de ordenamiento de la zona conurbana del Valle de México», Ciudad de México: Vivienda, año II, núm. 9, abril 1977, páginas 36-61. Complementariamente cabría mencionar, como trabajos de doctrina aplicada a la praxis nacional, sus estudios con Luis UNIKEL y otros, relativos a los planes directores de desarrollo metropolitano, elaborados para Supervisión Cervantes Asociados, S. A., respecto a Manzanillo (1975, 210 págs.), Tampico/Madero (1975, 214 páginas), Salina Cruz (1975, 215 págs.) y México (1975, 215 págs.).

\section{HACIA UN DERECHO ESTRUCTURAL}

En la Reunión Nacional sobre Población y Desarrollo Urbano, el 17 de febrero de 1976, en el marco del Instituto de Estudios Políticos y Sociales del PRI, Alarcón-Segovia presentó sus Bases para la planeación urbana: hacia un Derecho urbanistico estructural, en las cuales concluía con las recomendaciones siguientes:

«Es necesario legislar en el orden urbanístico en forma coherente y sistemática. La improvisación en estos aspectos engendra tan sólo disposiciones aisladas, sin un válido contenido normativo, que no son instrumentos idóneos de orden jurídico para la solución de problemas en el país. La propiedad urbana, por otro lado, debe de regularse buscando nuevas formas de tenencia, a fin de propiciar una reforma urbana integral, marco para la cabal gestación práctica de los planes del desarrollo urbano» (p. 136).

Estas conclusiones, necesariamente muy generales y en el marco de una Reunión en la cual las veintiuna ponencias resultaron sumamente "vagas», fueron, empero, acompañadas de precisiones referentes a vivienda y sistema político, a la teoría estructural del Derecho urbanístico, al planeamiento global y al derecho de propiedad, que parece oportuno poner aquí de manifiesto, como antecedente inmediato y sintético del importante Estudio indicado.

Para Alarcón, México es un país cuyas múltiples carencias se 
reflejan en la estructura urbana de todas y cada una de sus ciudades y del sistema general de asentamientos del país. Las principales ciudades del país carecen de los servicios suficientes, la necesaria infraestructura y el equipamiento mínimo para dar respuesta a las necesidades de sus habitantes, reflejándose el problema más agudo en la carencia de vivienda digna, que afecta a la población mayoritaria, siempre de escasos recursos. Por lo demás, graves desequilibrios regionales, tanto a nivel nacional como estatal, han sido provocados desde antaño por la primacía de centros a los que hoy confluye la desesperada masa de buscadores de trabajo y oportunidades:

"La problemática interurbana está causada así por un desajuste en el equilibrio de los centros e imbricada de contradicciones políticas, económicas y sociales que pueden, ante su relevancia, provocar ante cualquier observador el cuestionamiento de validez del sistema» (p. 137).

La legislación anterior a las enmiendas constitucionales federales de 1976 dio apenas pálidas respuestas ineficaces a la problemática interurbana. Según la teoría estructural, la plena eficacia del sistema normativo, referido a la problemática urbano-regional, previene que toda norma de planeación rectora del desarrollo deberá estar instrumentada mediante controles y estímulos, y que todo control y estímulo deberá justificarse en una norma de planeación jerárquicamente superior. Todo ello en el marco administrativo de la eficacia, regulado por disposiciones orgánicas y fiscales, y, en el marco procesal, por aquellas normas que regulen las acciones de defensa individual y las de exigencia frente a toda administración irresponsable.

Recordando que en los Estados Unidos Mexicanos se han elaborado infinitos planes, planes reguladores y proyectos urbanísticos que han carecido de la validez necesaria dentro del universo jurídico imperante, Alarcón apuntaba que el problema urbanístico está ligado fundamentalmente a la situación económico-social, por lo que toda regulación jurídica en lo urbano debe de encuadrarse en el marco de un plan de desarrollo económico y social, reglado asimismo por normas jurídicas.

Con rigor de verdadero jurista, y no de simple legista, señalaba que el factor determinante en nuestras sociedades es la propiedad, de cuyas desmembraciones y posibilidades depende, considerablemente, el sano desarrollo urbano: 
«Nada valdría el esfuerzo sistemático y conceptual establecido en leyes sin antes verter este concepto conforme a las necesidades insoslayables de nuevos moldes, a fin de llenar los huecos que conduzcan a una Reforma Urbana Integral. Si se continúa tropezando, en los loables afanes de vivienda y servicios para una población mayoritaria, con la irrestricta especulación inmobiliaria, todo esfuerzo de desarrollo urbano será inútil en su validez integral. Hay que considerar que la vivienda es un bien duradero de consumo necesario, y que la propiedad sobre el suelo deberá de regularse a todo nivel, imponiendo modalidades nuevas, politicamente ingeniosas, y escindiéndola de las casi brutales leyes de la oferta y la demanda" (página 142).

Ahora bien, la experiencia mexicana de Alarcón-Segovia perfila igualmente un antecedente indescuidable en un trabajo institucional que merece párrafo aparte.

\section{VIVIENDA Y PLANEACION NACIONAL}

En efecto, sus Lineamientos para la formulación de una política nacional de vivienda (3) planteaban bases para la formulación de una política de vivienda articulada a los grandes objetivos de una planeación nacional.

Sin detenernos en cada uno de estos Lineamientos, cabe aquí retener algunas consideraciones y posturas concretas, que permiten superar ciertas limitaciones aparentes del Estudio costarricense, derivadas de su metodología excesivamente monodisciplinaria.

Los Lineamientos coinciden con la Constitución española de 1978 (4). En efecto, abandonan la postura liberal y reclaman, de principio, una intensa acción del Poder público en materia económica, y, por ende, en el subsector de los cometidos de urbanismo $\mathrm{y}$ vivienda. "Si nos limitásemos a concebir las políticas de vivienda como un simple marco de lineamientos y criterios de acción estaríamos con ello circunscribiéndonos al campo de las buenas intenciones, y así, al de la ineficacia de la planificación idealista. La política, conceptualizada como el camino que asume el Estado para

(3) S.A.H.O.P.: Dirección General de Desarrollo Urbano y Vivienda/Subdirec. ción de Vivienda, mayo 1977, $57 \mathrm{ff}$.

(4) Cfr. la obra homónima, dirigida por Alberto Predieri y E. Garcfa dE ENTERRfA, Madrid: Civitas, 1980,880 págs., especialmente la contribución de Miguel SÁNCHEZ-MORÓN: "Notas sobre la función administrativa...", págs. 601-659, especial. mente págs. 646 y sigs. 
conducir las acciones y conductas sociales en el terreno de la vivienda, implica, en cambio, la necesidad de plantear objetivos viables y precisos, decisión de llevar a cabo las acciones propuestas, indicaciones de cómo hacerlo, integración de un marco instrumental adecuado, articulación del sector al plan general de desarrollo, etc. Tal concepto de política tiene, por tanto, un carácter de acto y no de simple guia o declaración» (ff. 1-2).

Existen dos teorías para enfocar el fenómeno de vivienda: una tradicional, que entiende el problema como un desequilibrio de la oferta y la demanda y encara la solución como un mayor número de unidades de producto terminado, realizado a través de la acción directa del Poder público o del sector privado organizado; una estructuralista, en la cual el problema no depende de la escasez de unidades de vivienda en el mercado, sino de la situación económica general y del nivel de desarrollo. Este último enfoque, al que adhiere nuestro autor, hace necesario dar prioridad al ingreso y sus formas de distribución, y lleva a sostener la insuficiencia de una politica habitacional limitada al enfoque de aspectos estrictamente físicos.

La lucidez lleva a recordar las siguientes cifras sectoriales de participación en la producción de vivienda:

\begin{tabular}{|c|c|c|}
\hline \multirow[b]{2}{*}{ SECTORES MEXICANOS } & \multicolumn{2}{|c|}{$\begin{array}{c}\text { PARTICIPACION EN LA } \\
\text { PRODUCCION DE VIVIENDA }\end{array}$} \\
\hline & $1950-1970$ & $1970-1976$ \\
\hline $\begin{array}{llllllll}\text { Público } & \ldots & \ldots & \ldots & \ldots & \ldots & \ldots & \ldots \\
\text { Privado } & \ldots & \ldots & \ldots & \ldots & \ldots & \ldots & \ldots \\
\text { Popular } & \ldots & \ldots & \ldots & \ldots & \ldots & \ldots & \ldots \\
\text { Popul } & \ldots & \ldots & \ldots & \ldots & \ldots\end{array}$ & $\begin{array}{r}7,8 \\
27,0 \\
66,0\end{array}$ & $\begin{array}{l}18,0 \\
16,5 \\
66,5\end{array}$ \\
\hline
\end{tabular}

La creciente participación del Poder público en la producción de vivienda en la década de los setenta (INFONAVIT, FOVIMI, FOVISSSTE, etc.) no ha aliviado al sector popular, quien sigue produciendo dos terceras partes de la vivienda del país. Más bien ha liberado al sector privado, cuya inversión habitacional se ha retraído para dirigirse especulativamente hacia áreas más rentables.

Si los recursos destinables a vivienda son limitados y en verdad escasos, frente a las grandes necesidades se abren otros aspectos del problema. 


\section{LO NORMATIVO COMO ESTORBO SOCIAL}

Como problema normativo $e$ instrumental, pobladores populares, promotores privados y hasta el sector público se ven estorbados por instrumentos jurídicos, administrativos, fiscales y financieros que no tienen relación con la dinámica del problema en su situación actual.

Así, el Código Civil reglamenta la propiedad de la vivienda y del suelo urbano y señala necesidades de registro y servicios notariales, que incrementan los gastos en forma incongruente con los propósitos sociales de la producción de la vivienda y dificultan y encarecen la transmisión de su tenencia. La Administración municipal desconoce la población popular asentada fuera del fondo urbano $y$ hostiliza los fraccionamientos irregulares ajenos a los ordenamientos vigentes; la ineficacia de ventanilla y la corrupción que todo lo matiza hacen de cualquier gestión de servicios (alineamiento, número oficial, agua, drenaje, etc.) una confrontación frecuentemente infructuosa. Los gravámenes fiscales a las utilidades excesivas derivadas de plusvalía o especulación inmobiliaria no están suficientemente generalizados en el país, debiendo orientar su ejercicio al desaliento del latifundismo urbano y al fomento de la acción de los pobladores populares. En lo financiero y crediticio son de observar las violaciones a las disposiciones del Banco Central en lo referente a gastos por apertura y otros que, indebidamente, se cargan al usuario por el concesionario bancario, para cuya actitud de lucro no importan los usuarios de crédito de baja condición económica, excluidos del juego de amplias garantías y de rigidez en los planes de financiamiento. En resumen, el andamiaje de las reglas de Derecho vigentes margina a más de dos terceras partes de la población (ff. 9-10) respecto del concepto ostentoso de «vivienda digna", diseñado por los técnicos consumistas, secretados por nuestras clases medias.

\section{LO HABITACIONAL, EFECTO Y NO CAUSA}

Además de estas problemáticas instrumental y conceptual, existen problemas de desajuste en el mercado y de distribución del ingreso. La producción formal actual ha resuelto el problema habitacional del 15 por 100 de la población del país, la mejor remune- 
rada, y pudiera hacerlo para otro 15 ó 18 por 100 más: tal es la demanda efectiva de las viviendas producidas, según los requisitos legales de adquirir tierra y según las normas y formas «modernas» de construcción y financiamiento; este desajuste apunta hacia el deterioro creciente de las condiciones habitacionales de los mexicanos, pasando el indice de hacinamiento de 4,9 habitantes por vivienda en 1950 a 5,5 en 1960, 5,8 en 1970 y a 6 según proyecciones para 1976; este deterioro se combina con las condiciones menguadas de habitabilidad que presentan las viviendas, cuyo índice pasa de un 30 por 100 de viviendas consideradas deficientes en 1935 a un 60 por 100 en 1952 y a un 70 por 100 en 1962. En lo cualitativo, en 1970, del total de viviendas: 41 por 100 tenían piso de tierra, 38 por 100 carecían de agua, 58 por 100 no disponían de drenaje, 41 por 100 carecían de electricidad. Complementariamente, el problema habitacional refleja los efectos de una creciente desigualdad en la distribución del ingreso y de los beneficios sociales, debiendo entendérselo en el centro de los conflictos específicos que articula, donde se perjudican las mayorías en beneficio de quienes controlan la producción de vivienda (capital hipotecario y financiero, industria de la construcción, dueños de la tierra) (ff. 11-15).

\section{HACIA LA SUPERACION DE UN DERECHO DE CLASE}

Por todo ello se impone una política que tienda a frenar el deterioro e impulsar el mejoramiento de las condiciones habitacionales, política de vivienda y desarrollo urbano que debe atravesar la sociedad completa y no limitarse a los sectores medios y asalariados, que puedan beneficiarse con los programas de «interés social». A ello contribuirán el financiamiento barato, la elevación de la productividad de la construcción, el control del mercado de materiales y del mercado del suelo: respecto de este último se apunta que «una regularización o dotación de tierra a bajo precio sin incidir sobre la libre disposición de la propiedad privada significa en última instancia favorecer a los llamados especuladores urbanos, quienes pueden realizar altas rentas no sólo en la zona inmediata, sino en cualquier otro sector urbano en el que posean tierra urbanizable» (f. 19).

El déficit de vivienda no puede explicarse sin considerar el déficit de empleo, el déficit del ingreso o el desequilibrio regional, para lo cual es necesario reconceptualizar la vivienda como factor de 
desarrollo económico, pues genera empleo, derrama salarios, activa la planta industrial.

Por lo demás, en auténtico jurista cuya visión sabe romper con las estrecheces del Derecho positivo, Alarcón se preguntaba:

"¿Cuál es la irregularidad en materia de poblamiento, el que los sectores de bajos recursos deban acceder a caminos considerados ilegales para darse un techo, o el que las normas e instrumentos en materia urbana y de vivienda no acepten nuestras realidades económicas y sociales más patentes?"

La respuesta es sugestiva:

«Una política de vivienda realista para el país hace necesario un cambio de actitud respecto a los conceptos de legalidad y normatividad que definen actualmente a la mayor parte de los asentamientos y viviendas populares como 'irregulares'. En primer término, es necesario reconocer que las formas de vivienda a las que el pueblo accede son las únicas alternativas ahora a su alcance; calificarlas, sin más, de irregulares es desconocer esa realidad y fomentar la corrupción. Pero también legitimar, sin más, su existencia conlleva el riesgo de institucionalizar la miseria y la explotación de los más débiles» (ff. 24-25).

\section{URBANISMO Y PARTICIPACION}

Su posgrado en la Complutense de Madrid lo vinculó con la Escuela democrática española de Derecho administrativo encabezada por el maestro Eduardo García DE ENTERRta, con su discípulo Ramón MARTín-Mateo y con los comentarios a la famosa Ley del Suelo de 12 de mayo de 1956, que se pronunciara expresamente en su Exposición de Motivos en favor de la propiedad pública del suelo, considerándolo como el «ideal" al que se renunciaba solamente por razones financieras; pronunciamiento éste que fuera recogido en la legislación más preocupada por los aspectos de participación y autogobierno en el mundo occidental, la legislación inglesa, cuyo libro blanco Land afirmara, en los setenta, que «un planeamiento positivo, capaz de controlar el proceso urbano y de decidir cuándo y dónde debe urbanizarse y edificarse, sólo es posible a partir de la propiedad pública del suelo». En esta misma línea, democratización del espacio urbano, se orientaron los Lineamientos cuando exigieron el replanteamiento de la estrategia gubernamental en materia de participación popular, la cual «constituye un ejercicio de- 
mocrático, ha sido mencionada en reiteradas ocasiones, pero su evocación no ha cristalizado en sugerencias concretas, sino en simples apuntamientos (...). La participación ciudadana deberá ser parte integrante de los procesos de adopción de decisiones (...). Debe reconocerse el derecho de las mayorias a participar en el control de la producción y el uso de su ámbito urbano, lo que en términos concretos significa que deben tener acceso a la planeación, decisión, ejecución y control de los planes que lo afecten» (f. 30).

\section{UN FALSO ATRIBUTO DE LA PROPIEDAD PRIVADA}

Las «líneas de acción prioritaria» (ff. 39-52) de los Lineamientos concluían con tres tipos genéricos de programas (de expansión, de consolidación y de regeneración urbanas), para resolver la vivienda de los sectores con ingresos hasta cuatro veces el salario mínimo, para regularizar la tenencia y para rehabilitar viviendas. Estas prioridades iban precedidas (ff. 35-36) de ricas consideraciones relativas a los usos del suelo y a la tenencia. La maximización del aprovechamiento de nuestros recursos instalados impide favorecer la tendencia natural de las zonas céntricas a un cambio de uso del suelo, el cual debiera evitarse, pues la desaparición de un uso poco rentable, el de la vivienda popular, significa no sólo la destrucción de un conjunto habitacional rehabilitado a costo relativamente bajo, sino un doble daño, primero a la economía de muchas familias beneficiarias de su ubicación céntrica, y segundo, un incremento de fuertes costos para la economía urbana global, al fomentarse la expansión irracional y altamente despilfarradora de nuestras ciudades. La seguridad en la tenencia de la vivienda es lo importante para el habitante urbano, y debe superarse la falsa identificación -impuesta por la propaganda de los mercaderes de casas- de dicha seguridad con la propiedad privada de la tierra: cualquier forma de tenencia que brinde seguridad es buena, incluso si se es arrendatario, en cuyo caso lo que el poblador requiere es la estabilidad espacial y financiera de que no será sacado al cabo de un año y de que no estará sujeto a incrementos de renta que le obliguen a ser un buscador perpetuo de vivienda.

Teniendo, pues, muy presentes las Bases para la planeación urbana de 1976 y estos Lineamientos de política de vivienda de 1977, podemos emprender un balance del Estudio que preside esta nota. 


\section{CONTENIDO FORMAL DE ESTA CONTRIBUCION}

El primer volumen del Estudio comprende: la Introducción (folios 1-6), donde el director explica los alcances y limitaciones de esta investigación indirecta, fundamentada en cuarenta y cinco disposiciones legislativas y reglamentarias costarricenses, tendente a la formulación de un Anteproyecto de Ley de Desarrollo y Ordenación urbana, apoyado en un Esquema general de adecuación administrativa en razón de la planeación; Hipótesis de trabajo, metodología y teoría estructural (ff. 143); y, finalmente, el Resumen-diagnóstico (ff. 1-100), donde se desglosa analíticamente la legislación costarricense, desde la Constitución hasta los reglamentos, agrupando críticamente las normas de planeación (ff. 11-35), las normas de control (ff. 35-53), las normas de fomento y servicios (ff. 53-68), las normas de administración (ff. 68-83), las normas de tributación (folios 84-98) y las normas procesales (ff. 98-99).

El segundo volumen comprende la ficha de elementos formales, la ficha de análisis de contenido normativo y la matriz de elementos regulantes y regulados, correspondientes a los primeros veintiséis ordenamientos considerados. Estos son:

A-1 Constitución política de la República de Costa Rica.

B-2 Ley de Planificación urbana.

C-3 Ley de Planificación nacional.

D-4 Ley de Construcciones.

E-5 Reglamento para el Control Nacional de Fraccionamientos y Urbanizaciones.

F-6 Ley de Erradicación de Tugurios y Defensa de sus Arrendatarios.

G-7 Código municipal.

H-8 Ley sobre División Territorial Administrativa.

I-9 Ley General de Salud.

J-10 Reglamento de Urbanización y Fraccionamiento de la Municipalidad del Cantón Central de la Provincia de San José.

K-11 Reglamento de Construcciones Urbanas para el Cantón Central de San José.

L-12 Reglamento General de Cementerios.

M-13 Reglamento de Instalación de Anuncios. 
$\mathrm{N}-14$ Ley de Aguas.

0-15 Ley de Inquilinato.

P-16 Ley de Propiedad Horizontal.

Q-17 Ley de Conservación del Patrimonio Histórico, Artístico y Cultural del País.

R-18 Ley General de Caminos públicos.

S-19 Ley que prohíbe a las Municipalidades enajenar tierras en las márgenes de los ríos o manantiales.

T-20 Ley de Tierras municipales.

U-21 Reglamento General de Mercados para el Cantón Central de San José.

V-22 Ley de Tránsito.

W-23 Ley de Estacionómetros.

X-24 Ley de Expropiaciones por Causa de Utilidad pública.

Y-25 Ley por la que se autoriza al Poder Ejecutivo a devolver a sus dueños aquellas propiedades expropiadas y no utilizadas por el Estado.

\section{Z-26 Ley de Protección y Desarrollo Industrial.}

Para tener una idea de la precisión del análisis, de la paciencia de benedictinos, puestas aquí de manifiesto por ALARCÓN-SEGOVIA y sus colaboradores, cabe señalar que, respecto de cada ordenamiento, las fichas y la matriz van seguidas de un prolijo desglose de elementos, que ejemplificamos seguidamente con la Ley de Planificación urbana de 15 de noviembre de 1968:

1. Datos generales, es decir: nombre completo del ordenamiento, fecha de promulgación, número de artículos, número de disposiciones transitorias, número de capítulos, número de títulos (secciones), fuente.

2. Antecedentes, es decir, los ordenamientos reformados, adicionados, derogados o abrogados por el propio texto del ordenamiento en estudio.

3. Estructura normativa, es decir, el enunciado de los diversos títulos o capítulos que componen el ordenamiento en cuestión. En otras palabras, su capitulado.

4. Caracteristicas destacadas del ordenamiento. Así, su definición como Ley-marco o Ley general; su cumplimiento de ciertos principios fundamentales en la técnica de las reglas de Derecho, 
tales como los de «norma estructurante» (es decir, prevención en su texto de los principios que deberán respetar las Entidades territoriales menores en la expedición de ordenamientos subordinados) o de "correlación normativa» (es decir, que esta regla planificadora subordina las reglas físicas, como estándares y prohibiciones, las reglas de control y fomento e incluso las reglas tributarias y procesales).

5. Objeto, es decir, la materia que se regula.

6. Naturaleza, consistente en la enunciación de los principales instrumentos reguladores que contiene el ordenamiento en estudio. Así, normas de planeación (planes de ordenación urbana, programas, sistema de planes, naturaleza jurídica de los planes, publicidad de los planes, contenido de los planes, procedimiento de elaboración de los planes, mención concreta de algunos estándares y prohibiciones importantes, etc.); normas de control (licencias, registro, garantías, certificado de ubicación, sanciones suspensivas); normas de fomento (fomento fiscal, régimen de expropiación); normas de administración, de tributación, procesales. Este punto permite la crítica del valor instrumental del ordenamiento.

7. Aplicación administrativa, donde se determina el órgano competente.

8. Jerarquía normativa, es decir, Ley-marco, Ley ordinaria, Reglamento, Circular, etc.

9. Organicidad normativa, es decir, otros ordenamientos importantes que, en forma tácita o expresa, tienen relación directa o indirecta con el precepto en análisis.

10. Ambito espacial y temporal de validez, es decir, si la regla se limita a alguna parte del territorio nacional o lo abarca por entero, y si ella tiene aplicación indefinida o sólo durante un término preciso.

Los datos de este análisis se vierten en una matriz general, en la que se indica, por medio de la numeración atribuida a cada ordenamiento en la forma arriba referida (v.g.: B-2, H-8, Z-26), qué Ley rige a qué problemática urbanística, a través de qué instrumento formal. Posteriormente, en base a esta matriz así llenada o completada, se realiza el resumen diagnóstico, fase final del trabajo, con miras a la elaboración del anteproyecto legislativo.

El tercer volumen comprende igualmente fichas y matrices, correspondientes a los restantes ordenamientos analizados. Estos son: 
A-27 Reglamento de normas mínimas para programas de vivienda económica.

B-28 Reglamento sobre señalamiento de obstáculos y restricciones a las construcciones dentro de la zona de protección de los aeródromos.

C-29 Ley por la que se autoriza a las Municipalidades para comprar terrenos donde establecer unidades industriales.

D-30 Ley sobre arrendamiento de locales municipales.

E-31 Ley del servicio nacional de electricidad.

F-32 Ley constitutiva del servicio nacional de acueductos y alcantarillado.

G-33 Ley Orgánica del Instituto Nacional de Vivienda y Urbanismo.

H-34 Ley de creación del Ministerio de Obras Públicas y Transportes.

I-35 Reglamento del sistema nacional de inversiones públicas.

J-36 Reglamento relativo a las funciones de la Comisión Técnica de Transportes.

K-37 Ley de organización y funcionamiento del Instituto de Fomento y Asesoría Municipal.

L-38 Ley de integración de Juntas directivas de instituciones autónomas.

M-39 Ley Orgánica del Ministerio de Salud.

N-40 Ley para la distribución del impuesto territorial.

0-41 Ley sobre la contribución para obras de interés público especial.

P-42 Ley del impuesto sobre los traspasos de bienes inmuebles.

Q-43 Ley del impuesto por el estacionamiento de vehículos en la vía pública.

R-44 Ley del impuesto territorial; y

S-45 Ley reguladora de la Jurisdicción Contencioso-administrativa.

Estos diecinueve ordenamientos son igualmente objeto del desglose de elementos señalado respecto de las reglas analizadas en el volumen segundo.

De este modo la materia prima de la concepción doctrinal y de la elaboración legislativa se contiene íntegramente en los volúmenes segundo y tercero, titulados Inventario normativo urbanistico de Costa Rica y análisis de su legislación. 
UNA CONTRIBUCION MEXICANA Y COSTARRICENSE AL DERECHO URBANISTICO...

El cuarto volumen comprende tres partes:

La Parte I, Esquema general de adecuación administrativa en razón de la planeación (ff. 1-38), donde los autores, inspirándose en la Ley Orgánica de la Administración pública federal mexicana, de 29 de diciembre de 1976, pero mejorándola, se plantean la articulación de la planeación, tanto económica como urbanística, con los órganos centralizados y descentralizados del Poder público.

La Parte II, Anteproyecto de Ley de Desarrollo y Ordenación urbana para la República de Costa Rica (ff. 1-89), cuyos 157 artículos comprenden cinco títulos, que abarcan los capítulos indicados seguidamente entre paréntesis: el Título I, Objeto y regímenes urbanisticos; el Título II, Del régimen de planeación (del sistema de planes, del contenido de los planes, de la naturaleza jurídica de los planes y de sus efectos, del procedimiento para elaboración de los planes); el Título III, Del régimen del suelo; el Título IV, Del régimen de modalidades y limitaciones a la propiedad privada (de las modalidades al uso, modalidades al disfrute, modalidades a la disposición, de las restricciones, intervención del Estado en la edificación y en los desarrollos urbanísticos); y, finalmente, el Título V, Del régimen de actuación (de la expropiación, la ocupación temporal y las limitaciones al dominio).

La Parte III cierra la obra con un Indice cruzado de la legislación urbanística de la República de Costa Rica (ff. 1-76).

\section{EL «ESTUDIO»Y SU DOCTRINA}

En América latina la evolución explosiva de las ciudades en el tercer cuarto del siglo $\mathrm{xx}$ no ha sido seguida por una consideración atinada de su problemática, por la enseñanza universitaria y la investigación. Todavía a fines de la década de los sesenta carecíamos de la más mínima literatura al respecto, cuando ya, además de numerosas monografías y contribuciones en la Revista de Administración Pública, L. Alegría editaba desde 1976 la Revista de Derecho Urbanístico, que en estos días publica su número 70 . La aproximación al tema se ha venido realizando por atajos no muy coherentes con el objeto de la materia en estudio, tales como el Derecho de la construcción y, fundamentalmente, el Derecho municipal (clásicos estudios de Bielsa, Prates da Fonseca, Sayagüés-Laso). El Estudio dirigido por ALARCóN-SEgovia viene a fundar, tanto para los Estados Unidos Mexicanos como para Costa Rica, el Derecho urba- 
nístico como disciplina científica, precisando su objeto y la especificidad de su método, conceptos e instrumentos.

El Derecho urbanístico es presentado como el conjunto de normas juridicas, preponderantemente de Derecho público, que regulan las conductas que inciden directa o indirectamente en el proceso del crecimiento, estructura y cambio físico de los asentamientos, a través de la creación, utilización y apropiación del espacio (I, ff. 11-12). Desde el antiguo Egipto (inscripción de Tel-el-Amarna) hasta los Códigos civiles europeos y latinoamericanos del siglo xIX —quizá con la excepción aquí omitida del Derecho de los antiguos pueblos germánicos- la regulación del espacio se fundamenta en las diferentes formas de detentación del suelo urbano, basadas en el criterio casi irrestricto del derecho de propiedad, que sistematizaran los romanos. Después de la Primera Guerra mundial, y señaladamente en forma concomitante y posterior a la crisis de 1929, la multiplicación de los cometidos del Poder público, que lo convierten en gestor y prestador de servicios, lleva al surgimiento de las modernas instituciones que tienden, o deben tender, a la sustitución de la autonomía de la voluntad en los fenómenos de utilización, producción $y$ apropiación del espacio (ff. 2-3).

Frente a la crisis urbana, que no es privativa de los países del Tercer Mundo, sino que se manifiesta igualmente en las economías dominantes, se produce una profusa actividad reglamentaria que conlleva a las primeras elaboraciones sistemáticas en Europa occidental. De éstas extrae este Estudio la madurez de sus fundamentos y motivaciones comparativos, de esa rica y azarosa experiencia europea recoge el legislador las instituciones que rigen esta nueva rama del Derecho; el administrador encuentra, asimismo, instrumentos de aplicación; el Juez, criterios de interpretación a la luz de principios renovados, y, finalmente, el teórico y la doctrina podrían hallar criterios diferenciales de actividad para la ciencia jurídica.

\section{EL OBJETO DEL DERECHO URBANISTICO}

Las conductas humanas que son objeto del Derecho urbanistico inciden sobre el espacio, creándolo, utilizándolo o apropiándolo. Las conductas creadoras, de condiciones para el asentamiento humano, van desde la delimitación territorial de un futuro centro de población y la construcción de su infraestructura hasta la construcción 
o demolición de una vivienda privada, mediante actos tanto públicos como privados. Las conductas de utilización del espacio, en cuanto bien de consumo duradero, se distinguen de las conductas agrarias, en cuanto el hombre lo consume sin producir, necesariamente por este acto de consumo, ningún otro bien de importancia económica; estas conductas se manifiestan desde la simple diferenciación entre uso público y privado (5) hasta los preceptos contractuales o reglamentarios relativos al uso y fines de un edificio, de las vías públicas o de las áreas urbanas. Las conductas de apropiación, determinantes en la estructura física de las ciudades y tradicionalmente reguladas por los Códigos civiles, van desde un decreto de expropiación o de nacionalización hasta la compraventa o permuta de un inmueble.

Estas conductas humanas pueden tener incidencia directa o indirecta sobre el espacio. Incidencia directa tienen aquellas conductas que pueden fraccionar un lote de terreno, construir una casa, decretar una expropiación, establecer un uso o una reserva, adquirir un bien inmueble, conservar un monumento, etc. Incidencia indirecta tienen aquellas conductas urbanísticas que condicionan la forma y estructura de los asentamientos, al establecer un conjunto de situaciones específicas que las afectan; así, el Derecho administrativo regula las formas administrativas que determinan la acción urbanística; el Derecho fiscal regula las formas de tributación y recaudación ejercidas sobre las conductas o en razón de ellas; el Derecho procesal genera las condiciones que permiten la exigencia o la defensa respecto de una conducta que concierne a un interés. juridicamente tutelado. Son las conductas relativas a la organización, funcionamiento y controles de las Administraciones públicas, que en todos los países estructuran instituciones, atribuyen facultades urbanísticas a las colectividades territoriales, establecen impuestos (prediales, de traslación de dominio, de plusvalía, etc.), crean recursos administrativos o verdaderos juicios contencioso-administrativos, en los cuales se legitima el «derecho a la ciudad» en la contraposición de los intereses público y privado (ff. 1-11).

Partiendo de la severa división del trabajo técnico-jurídico indicada más arriba (división que criticábamos por «empobrecerlo", pero que, en este caso, es fundamento directo del rigor alcanzado), AlaRcón parte de una estricta autolimitación: su ámbito material

(5) Destinos y usos, en la terminologa de la Ley Federal mexicana de 1976, artículo 37. 
de interés son aquellas reglas de derecho que rigen los cometidos del Poder público en cuanto a acción directa, prestación de servicios $y$ actos de control respecto al agente privado. Siguiendo a la reciente doctrina española en el pensamiento del ilustre rector de Bilbao, el profesor Ramón MARTíN-MATEO, se consideran de interés las determinaciones jurídicas tanto positivas como negativas: las positivas, de prestación de servicios y acción directa, y las negativas, tendentes a la limitación de la conducta de los particulares (folio 13).

\section{LOS ACTOS «URBANISTICOS» DEL PODER PUBLICO}

De esta forma, el cometido urbanístico del Poder público presenta cinco tipos de actos cuyo contenido es relevante para este Estudio. Siguiendo la clásica doctrina francesa, los actos de autoridad y los actos de gestión, aquí llamados actos de orden y actos de servicio. Pero, además, tenemos los actos de planificación, que establecen provisoriamente las metas y objetivos a los que la comunidad habrá de dirigirse para la obtención de satisfacciones y fines propios. También los actos controladores del Poder público, que sujetan las conductas de los particulares mediante reglas coercitivas. Finalmente, se plantean como objeto de interés los actos de carácter indicativo, consistentes en exenciones, subsidios, estímulos, fomentos o en prestaciones directas de servicios. En resumen, emergen como originales de esta nueva disciplina, los llamados actos de planeación, de control y de fomento.

Ahora bien, la acción del Poder público se complementa en esta materia con actos administrativos, financieros (en sentido amplio) $y$ procesales. En primer lugar, la Administración dicta actos de autorregulación, por los cuales el Poder público se fija a sí mismo sus formas de organización y funcionamiento; en segundo lugar, se dictan actos de tributación, mediante los cuales se recaudan los recursos en dinero o en especie para el sostenimiento económico-financiero del Poder público y para el cumplimiento de sus cometidos sociales; $\mathrm{y}$, finalmente, actos de carácter procesal, a través de los cuales se crean garantías jurídicas para que el ciudadano exija el cumplimiento de las prestaciones administrativas y sociales o se defienda mediante acciones o excepciones procesales relativas al interés legítimo afectado (I, ff. 13-17). 


\section{LIMITACIONES CONCEPTUALES: TECNICA JURIDICA NUEVA Y SISTEMA TRADICIONAL}

Párrafo aparte merecen las limitaciones que derivan, para la expansión técnica del Derecho urbanístico, del propio sistema jurídico tradicional.

En primer lugar, y partiendo del Derecho positivo vigente en Costa Rica - cuyas insuficiencias podemos hoy considerar comunes a la mayoría de los países latinoamericanos-, el Derecho civil clásico comporta un régimen de propiedad inmobiliaria, carente de un efectivo control público, mediante la imposición de modalidades y limitaciones. En un sistema liberal, que es hoy una antigualla, el régimen de propiedad obedece en forma casi irrestricta a la autonomía de la voluntad, a través de las facultades de usar, disfrutar y disponer de la misma. Por ello, las limitaciones y modalidades legales son muy escasas, reduciéndose a imponer criterios respecto al uso del suelo por vía de la zonificación, o simplemente a determinar estándares urbanísticos a la edificación.

Ahora bien, respecto a la propiedad privada existe una indefinición peligrosa en los conceptos, ciertamente diferenciables, de modalidad a la 'propiedad, de limitación de dominio y de restricciones urbanisticas. La modalidad o modo de ser que legislativamente o con fundamento legislativo se impone a la propiedad para adecuarla a las necesidades económicas del momento no es necesariamente limitativa para el titular del dominio, sino que en ocasiones lo beneficia, como es el caso de las modalidades de inembargabilidad y de imprescriptibilidad de los bienes que integran el patrimonio del Poder público; así, se distingue entre modalidades al uso, modalidades al disfrute y modalidades a la disposición (IV, arts. 95 a 122, folios 55-70). En este sentido, es erróneo considerar como sinónimos a los términos de modalidad, por una parte, y de limitación, por la otra: la modalidad, sin derecho a indemnización, puede ser impuesta por vía administrativa-reglamentaria, mientras que la limitación de dominio es resuelta en un reglamento, pero por haber sido prevista en la Ley, y tampoco dará lugar a indemnización alguna (ibidem, IV, art. 154, f. 88). Las restricciones urbanísticas constituyen la aplicación al caso concreto de las modalidades y limitaciones previstas en leyes y reglamentos: ellas son llevadas a cabo por vía administrativa, reglamentariamente o por convenio. 
En segundo lugar, algunos principios generales del Derecho, tales como la relación entre norma general y norma especial, o como la igualdad estricta ante la Ley, se ven afectados por los beneficios y cargas, no siempre equivalentes, que derivan de los actos de planeación. Se puede correr el peligro de que la asignación de usos diferenciales al suelo urbano como limitaciones de dominio sean consideradas como figuras semejantes a la expropiación, obligando al Poder público a indemnizar, lo cual no sólo sería sumamente oneroso, sino que imposibilitaría las acciones tendentes al desarrollo urbanístico (I, f. 25).

En tercer lugar, la multiplicación de los cometidos del Poder público en función administrativa ha llevado a la forma de una casi ilimitada "galaxia» de dependencias centralizadas y de Entidades paraestatales, sin ninguna sistemática ni organicidad, lo cual conlleva la "selva legislativa" que padecemos, por lo cual deberán de buscarse los principios que rijan estructuradamente a esta multitud de reglas de Derecho, para simplificar su interpretación, ejecución y jurisdicción. Más aún que la simple codificación urge reducir el número de leyes, subsumiéndolas unas en otras, para evitar los desfavorables efectos del caos normativo, que conduce a la ineficacia administrativa, a la injusticia social y a la inseguridad jurídica.

En cuarto lugar, cabe finalmente aludir al ya clásico problema de la naturaleza jurídica y rango normativo de los actos de planificación, precursoramente estudiado por el profesor español José María Chillón-Medina (6). El urbanismo cuenta con una serie de instrumentos de acción: planes, proyectos, programas. La mayor parte de las leyes costarricenses en vigencia mencionan estos instrumentos, pero sin asignarles naturaleza juridica definida. Surge así el problema de su validez y obligatoriedad respecto a gobernantes y gobernados, ya que antes del Anteproyecto de este Estudio (Tomo IV) no podía definirse si un plan de urbanismo es un reglamento, un decreto o tan sólo un acto administrativo de eficacia general. Por lo que ya se vio respecto a modalidades de la propiedad y a limitaciones de dominio, debe darse contenido formal a estos instrumentos, incluyéndolos jerárquicamente en el universo de las reglas de Derecho (I, f. 27).

(6) Cfr. sus trabajos «Sobre el valor en derecho de los planes económicos...", en Homenaje a Sayagüés-Laso, Madrid: IEAL, 1969, y Montevideo: Amalio M. Fernández, 1976, tomo V, págs. 383-507; y «Formas, técnicas y estructuras administrativas ante la planificación económica», Madrid: Revista de Administración Pública, 1971, núm. 64, págs. 107-178. 


\section{DE LAS LIMITACIONES ESTRUCTURALES}

Para concluir, y sin perjuicio de algunas reservas menores, parece oportuno destacar la sistematización macrosectorial de los cometidos del Poder público (IV, ff. 3-22), que supera a su modelo de la Ley federal mexicana de 1976, y el lúcido análisis de las dificultades que enfrenta el Derecho urbanístico, en su consolidación como disciplina científica.

Además de las indicadas limitaciones conceptuales del Derecho clásico, existen limitaciones estructurales: políticas, económicas, sociales y de teoria del Estado. Hay impreparación en los grupos que ejercen la Administración pública y carecemos de cuadros técnicos para una problemática difícil y novedosa, lo cual se agrava porque la discontinuidad política en regímenes democráticos como el de Costa Rica genera acciones legislativas discontinuas, desestructuradas y contradictorias. El interés político de permanencia en el Poder de un determinado partido subordina a este elemento cualquier consideración de carácter social, económico o técnico: se soslayan así soluciones impostergables, a fin de evitar la confrontación contra factores reales de poder, que pueden inclinar la balanza electoral hacia uno $u$ otro partido.

La situación económica de crisis recurrente que viven los países capitalistas dependientes lleva a la constante expedición de leyes, que crean órganos de la más diversa índole, con facultades contradictorias, parciales o repetitivas. Ahora bien, como la economía no se encuentra planificada y obedece fundamentalmente a intereses de clase, las leyes son asimismo asistemáticas, incoherentes y se manifiestan o bien como la expresión formal del interés económico dominante o bien como un pálido remedio a males económicos y sociales que el Poder público no puede, o no quiere, encarar. La dispersión normativa es entonces notable, asfixiada la legislatura por la elaboración de disposiciones de objeto sumamente específico, que deberían estar contenidas en ordenamientos globales más amplios (I, ff. 19-20).

La elaboración legislativa suele ser más lenta que los avances tecnológicos o que los procesos de organización y concientización social. Las disposiciones técnicas del urbanismo no parecen diseñadas para un proceso de adaptación a los cambios de la vida social; pero, además, a la dificultad técnica se suma la desorganización social y cierta irresponsabilidad de grupos organizados que pa- 
recen interesados en la creciente obsolescencia de las disposiciones urbanísticas.

Finalmente, la proliferación legislativa derivada de la explosión de los cometidos del Poder público y de la expansiva "galaxia» de las instituciones administrativas que los asumen, nos lleva a internarnos en esta "selva» con la actitud del resignado viajero que, habiendo dedicado su vida a explorarla, sólo ha llegado a conocerla parcialmente (I, ff. 20-22).

\section{UN NUEVO DIALOGO}

Al comentar la obra de VALNER (7) se apuntaba la excepcional aportación técnica de Alarcón-Segovia (8). La inesperada desaparición del joven maestro le sorprende en su plenitud intelectual, en el momento mismo en el cual, cumplida la forja de su honda cultura y de su instrumental técnico, iba a emprender la redacción de una contribución general sobre esta materia. Su obra habría sido coronada, pero tal cual subsiste en sus publicaciones, y, muy particularmente, en este Estudio, ella se basta a sí misma.

En efecto, la presencia del profesor mexicano en la bibliografía latinoamericana sustenta un diálogo, que no siempre ha sido fácil, a causa de la falta de un lenguaje común. De él puede decirse que ha cumplido con la ambición capital de nuestra más reciente doctrina (9):

«Ha contribuido a romper la barrera de incomunicación que viene separando a quienes hacen el urbanismo y quienes lo padecen, y ha acercado todo lo posible a sus múltiples agentes y destinatarios el conocimiento del Derecho, de un Derecho que por su complejidad sigue siendo, en muy buena parte todavía, un secreto compartido por muy pocas personas».

(7) Gregorio VaLneR-ONJas (coordinador): Reunion nacional sobre el sector asentamientos humanos, urbanismo y vivienda, Ciudad de México: IEPES del PRI, 1976.

(8) Cfr. Ciudad de México: Vivienda, núm. 5, agosto 1976, págs. 120 y sigs.

(9) Cfr. Tomás-Ramón FernándeZ: Manual de Derecho urbanistico, Madrid: Abella/El Consultor, pág. 9. 